\title{
Association of sleep duration with type 2 diabetes and impaired glucose tolerance
}

\author{
J.-P. Chaput • J.-P. Després • C. Bouchard • A. Tremblay
}

Received: 25 February 2007 / Accepted: 1 July 2007 / Published online: 24 August 2007

(C) Springer-Verlag 2007

\begin{abstract}
Aims/hypothesis The aim of this study was to assess the relationship between sleep duration and type 2 diabetes or impaired glucose tolerance (IGT).

Methods Anthropometric measurements and self-reported sleep duration were determined in a cross-sectional sample of 323 men and 417 women aged 21-64 years from the Quebec Family Study. Glucose homeostasis indicators were compared between short (5-6 h), 'normal' (7-8 h) and long (9-10 h) sleeper groups.

Results Using adults with 7-8 $\mathrm{h}$ of sleep as a reference, the adjusted odds ratio for type 2 diabetes/IGT was 1.58 (1.132.31) for those with 9-10 $\mathrm{h}$ of sleep and 2.09 (1.34-2.98) for those with 5-6 h of sleep, after adjustment for potential confounding variables. The short and long sleepers presented significantly higher total insulin AUC $(p<0.05)$, whereas total glucose AUC was not different between the three sleeper groups in both sexes. The mean glucose area below fasting glucose concentrations was significantly higher in short $(p<0.01)$ and long sleepers $(p<0.05)$ compared with
\end{abstract}

\footnotetext{
J.-P. Chaput • A. Tremblay $(\bowtie)$

Division of Kinesiology,

Department of Social and Preventive Medicine,

Faculty of Medicine, Laval University,

Quebec City, Quebec, Canada

e-mail: angelo.tremblay@kin.msp.ulaval.ca

J.-P. Després

Quebec Heart Institute,

Hôpital Laval Research Center, Hôpital Laval,

Quebec City, Quebec, Canada

C. Bouchard

Human Genomics Laboratory,

Pennington Biomedical Research Center,

Baton Rouge, LA, USA
}

'normal' sleepers, and significantly higher in short $(p<0.05)$ compared with long sleepers in both sexes.

Conclusions/interpretation The present study provides evidence that short- and long-duration sleep times are associated with type 2 diabetes/IGT in adults, even after adjustment for several confounders. These results also showed that the lower glucose concentrations at the end of the OGTT were observed in short sleepers. According to the glucostatic theory of appetite control, this represents a stimulus that can trigger episodes of hunger and spontaneous food intake, which may explain at least in part the greater risk of overweight displayed by short sleepers, as shown in previous studies.

Keywords Energy intake - Glucose homeostasis . Glycaemia $\cdot$ Sleep loss $\cdot$ Weight gain

$\begin{array}{ll}\text { Abbreviations } \\ G_{\mathrm{ABF}} & \begin{array}{l}\text { glucose area below fasting glucose } \\ \text { concentrations } \\ \text { homeostasis model assessment of insulin } \\ \text { HOMA-IR } \\ \text { resistance }\end{array} \\ \text { IGT } & \begin{array}{l}\text { impaired glucose tolerance } \\ \text { ORdds ratio }\end{array}\end{array}$

\section{Introduction}

Lack of sleep has become a widespread habit driven by the demands and opportunities of the modern '24-hour' society. Nearly one-third of adults report sleeping $<6 \mathrm{~h}$ per night, leading some to suggest that we live in a sleep-deprived society [1]. Factors responsible for this situation include increases in environmental light, longer work days/longer commuting time, an increase in evening and night work, and 
the advent of television, the personal computer and the Internet [2]. Not surprisingly, reports of fatigue and tiredness are more frequent today than a few decades ago [3].

Large-scale studies have shown that short- and longduration sleep times are independently associated with an increased risk of coronary events, symptomatic diabetes and mortality risk [4-7]. In these studies, a daily sleep duration of $7 \mathrm{~h}$ was associated with minimal mortality and the lowest prevalence of adverse events. Short sleep duration was also associated with overweight and obesity in adults [8-13]. Importantly, it was shown that the neuroendocrine control of appetite was affected, as plasma levels of the anorexigenic hormone leptin were decreased, whereas levels of the orexigenic factor ghrelin were increased $[9,10]$. These neuroendocrine changes were associated with increased hunger and appetite, which might lead to overeating and weight gain [9].

In a recent study, we have shown that short sleep duration predicts an increased risk of being overweight or obese in adults [13]. Furthermore, we found that it was the lack rather than the excess of sleep time that affected body weight and adiposity indices in greater proportions. Here we extend this study to the relationship between sleep duration and type 2 diabetes or impaired glucose tolerance (IGT), considering that chronic sleep loss has become a prevailing condition in Western societies and that the potentially adverse influences of sleep loss on metabolic regulation represent an issue of increasing clinical relevance.

\section{Methods}

Participants The Quebec Family Study was initiated at Laval University in 1978 [14]. The primary objective of this study was to investigate the role of genetics in the aetiology of obesity and related cardiovascular risk factors. The 223 Europid nuclear families (951 participants) involved in the entire study (phases 1,2 and 3) were recruited through the media and were all French Canadians from the greater Quebec City area. Because no OGTTs were performed in phase 1, the present analyses were from participants involved in phases 2 and 3 of the Quebec Family Study, conducted between 1989 and 2001. Thus, individuals who participated in phase 2 or phase 3 and who were between 21 and 64 years of age were selected for cross-sectional analyses (323 men and 417 women). Additional inclusion criteria were: (1) to be nonsmoker; (2) not to be pregnant; (3) to have had a stable body weight ( $\pm 2 \mathrm{~kg}$ ) over the 6 months preceding testing; and (4) to be free of eating disorders. All participants gave written informed consent. The study was approved by the Medical Ethics Committee of Laval University.

Sleep duration assessment The number of hours of sleep was assessed through a question inserted into a self- administered questionnaire on physical activity participation. The question formulation was: 'On average, how many hours do you sleep a day?' Owing to the fact that only two participants (one man and one woman) reported sleeping $4 \mathrm{~h} /$ day and five participants (two men and three women) reported sleeping 11 or $12 \mathrm{~h} /$ day and that the majority of participants reported sleeping 7 or $8 \mathrm{~h} /$ day, we decided to classify the participants into three sleep duration groups in order to have adequate statistical power and to be in agreement with our recent paper [13]. These groups are: short sleepers (5-6 h of sleep; 42 men and 42 women), 'normal' sleepers (7-8 h of sleep; 239 men and 292 women) and long sleepers (9-10 h of sleep; 42 men and 83 women). Since our recent study reported significantly lower adiposity indices in the 7-8 $\mathrm{h}$ than in the 5-6 $\mathrm{h}$ sleeping group in both sexes [13], the present analyses were an attempt to further document this difference.

Anthropometric and body composition measurements Body weight, height and waist and hip circumferences were measured according to standardised procedures recommended at the Airlie Conference [15], and the waist-to-hip ratio was calculated accordingly. BMI was calculated as body weight divided by height squared $\left(\mathrm{kg} / \mathrm{m}^{2}\right)$. Body density was obtained from the mean of six valid measurements derived from underwater weighing [16]. Before immersion in the hydrostatic tank, the helium dilution method of Meneely and Kaltreider [17] was used to determine the pulmonary residual volume. The percentage of total body fat was determined from body density with the equation of Siri [18]. Body fat mass was estimated from body weight and the percentage of body fat.

OGTT A 75 g OGTT was performed in the morning after a $12 \mathrm{~h}$ overnight fast. Blood samples were collected in tubes containing EDTA and Trasylol (Miles Pharmaceutics, Rexdale, ON, Canada) through a venous catheter from an antecubital vein at $-15,0,15,30,45,60,90,120,150$ and $180 \mathrm{~min}$. Plasma glucose concentration was measured enzymatically [19], whereas plasma insulin concentration was determined by RIA with polyethylene glycol separation [20]. Fasting insulin and glucose concentrations were calculated as the mean of the -15 and 0 min concentrations.

The total glucose or insulin AUC and the glucose area below fasting glucose concentrations $\left(G_{\mathrm{ABF}}\right)$ were calculated by the trapezoidal method. We also calculated the homeostasis model assessment of insulin resistance (HOMA-IR) index [21].

Assessment of the risk of type 2 diabetes/IGT with short sleep duration Type 2 diabetes and IGT were defined in accordance with the American Diabetes Association and the World Health Organization criteria [22, 23]. We defined 
Table 1 Descriptive characteristics of men and women in the study

\begin{tabular}{lll}
\hline & Men $(n=323)$ & Women $(n=417)$ \\
\hline Age (years) & $41.5 \pm 13.7$ & $41.2 \pm 12.9$ \\
Weight $(\mathrm{kg})$ & $82.7 \pm 19.7$ & $71.9 \pm 22.4^{\mathrm{a}}$ \\
BMI $\left(\mathrm{kg} / \mathrm{m}^{2}\right)$ & $27.5 \pm 6.5$ & $27.9 \pm 8.8$ \\
Body fat mass $(\mathrm{kg})$ & $20.6 \pm 13.3$ & $24.5 \pm 15.3^{\mathrm{a}}$ \\
Body fat $(\%)$ & $23.4 \pm 9.1$ & $32.3 \pm 10.5^{\mathrm{a}}$ \\
Waist circumference (cm) & $94.4 \pm 16.6$ & $84.7 \pm 19.0^{\mathrm{a}}$ \\
Waist-to-hip ratio & $0.93 \pm 0.08$ & $0.79 \pm 0.08^{\mathrm{a}}$ \\
Total sleep duration (h) & $7.6 \pm 1.0$ & $7.8 \pm 1.1$ \\
\hline
\end{tabular}

Values are means $\pm \mathrm{SD}$

${ }^{a}$ Significantly different from men $(p<0.01)$

type 2 diabetes as use of insulin or a hypoglycaemic agent, a fasting plasma glucose level $\geq 7.0 \mathrm{mmol} / \mathrm{l}$, or a $2 \mathrm{~h}$ postload plasma glucose level $\geq 11.1 \mathrm{mmol} / 1$. On the other hand, IGT was defined as a $2 \mathrm{~h}$ postload plasma glucose level of $\geq 7.8 \mathrm{mmol} / \mathrm{l}$ in participants not meeting the criteria for type 2 diabetes. In addition, a broad set of potential confounding variables were measured via self-reported questionnaires. These included age, marital status, employment status, educational level, annual household income, physical activity level, alcohol intake, coffee intake, energy intake, hypertension and heart disease.

Statistical analysis An unpaired Student's $t$ test was used to compare means of descriptive characteristics between men and women. Multivariate logistic regression analysis was performed separately by sex and for both sexes combined to evaluate the strength of the relationship between sleeping hours and type 2 diabetes/IGT after adjustment for the above-mentioned confounding variables. An analysis of covariance was also performed in order to compare means of glucose homeostasis indicators between short, 'normal' and long sleepers after adjustment for the above-mentioned confounding variables. In addition, we controlled for BMI, per cent body fat and waist circumference (one at a time) in order to determine if the adjustment for any of these adiposity indices attenuate the association of sleep time with type 2 diabetes/IGT. In the presence of a significant effect, Tukey's post hoc test was performed to determine which groups were significantly different. Because some individuals in this family study are closely related, we adjusted for clustering in the analyses to avoid underestimation of SDs using the generalised estimating equations statistical method [24]. Data are given as means \pm SD unless otherwise noted. Statistical significance was set at a $p$ value $<0.05$. All statistical analyses were performed using the JMP version 3.2.2 program (SAS Institute, Cary, NC, USA).

\section{Results}

Table 1 shows descriptive characteristics of participants. As expected, men had higher body weight, waist circumference and waist-to-hip ratios than women, whereas women had greater body fat mass and percentage of body fat than men. However, age, BMI and total sleep duration were not significantly different between sexes.

Table 2 shows the relationship between short sleeping hours and type 2 diabetes/IGT after adjustment for potential confounders. In the model using adults with $7-8 \mathrm{~h}$ of sleep as a reference, the adjusted odds ratio (OR) for type 2 diabetes/IGT was $1.58(1.13-2.31)$ for those with $9-10 \mathrm{~h}$ of sleep and 2.09 (1.34-2.98) for those with 5-6 h of sleep. The adjustment for confounders did not weaken the observed associations between sleep duration and type 2 diabetes/IGT.

Table 2 Relationship between sleep duration and type 2 diabetes mellitus or IGT

\begin{tabular}{|c|c|c|c|c|c|c|c|}
\hline & \multicolumn{3}{|l|}{ Men $(n=323)$} & \multicolumn{3}{|l|}{ Women $(n=417)$} & \multirow{2}{*}{$\begin{array}{l}\text { Both sexes } \\
\text { Multivariate }^{\mathrm{b}} \\
\text { OR }(95 \% \mathrm{CI})\end{array}$} \\
\hline & $\begin{array}{l}\text { Type } 2 \text { diabetes/ } \\
\text { IGT }(n)\end{array}$ & $\begin{array}{l}\text { Type } 2 \text { diabetes/ } \\
\text { IGT }(\%)\end{array}$ & $\begin{array}{l}\text { Multivariate }^{\mathrm{a}} \\
\text { OR }(95 \% \mathrm{CI})\end{array}$ & $\begin{array}{l}\text { Type } 2 \text { diabetes/ } \\
\text { IGT }(n)\end{array}$ & $\begin{array}{l}\text { Type } 2 \text { diabetes/ } \\
\text { IGT }(\%)\end{array}$ & $\begin{array}{l}\text { Multivariate }{ }^{\mathrm{a}} \\
\text { OR }(95 \% \mathrm{CI})\end{array}$ & \\
\hline \multicolumn{8}{|c|}{ Sleeping time $(\mathrm{h})$} \\
\hline $5-6$ & 12 & 28.6 & $2.27(1.47-3.28)$ & 11 & 26.2 & $1.82(1.25-2.63)$ & $2.09(1.34-2.98)$ \\
\hline $7-8$ & 30 & 12.6 & 1.00 & 42 & 14.4 & 1.00 & 1.00 \\
\hline $9-10$ & 8 & 19.0 & $1.51(1.10-2.44)$ & 20 & 24.1 & $1.67(1.16-2.39)$ & $1.58(1.13-2.31)$ \\
\hline$p$ value $^{\mathrm{c}}$ & & & $<0.05$ & & & $<0.05$ & $<0.05$ \\
\hline
\end{tabular}

${ }^{\mathrm{a}}$ The adjusted ORs calculated separately by sex

${ }^{\mathrm{b}}$ The adjusted ORs for both sexes combined. ORs were adjusted for age, marital status, employment status, educational level, annual household income, physical activity level, alcohol intake, coffee intake, energy intake, hypertension, heart disease and waist circumference. Results were not materially different after controlling for BMI or per cent body fat instead of waist circumference

${ }^{\mathrm{c}} 5-6 \mathrm{~h}$ and $9-10 \mathrm{~h}$ sleeping groups vs $7-8 \mathrm{~h}$ sleeping group (referent group) 
Table 3 Differences for some glucose homeostasis indicators between short (5-6 h), 'normal' (7-8 h) and long (9-10 h) sleeper groups of men

\begin{tabular}{llll}
\hline & \multicolumn{2}{l}{ Sleeping time $(\mathrm{h})$} & \\
\cline { 2 - 4 } & $5-6(n=42)$ & $7-8(n=239)$ & $9-10(n=42)$ \\
\hline Fasting glucose level $(\mathrm{mmol} / \mathrm{l})$ & $5.81 \pm 0.76^{\mathrm{a}}$ & $5.32 \pm 0.62$ & $5.53 \pm 0.79^{\mathrm{a}, \mathrm{b}}$ \\
Fasting insulin level $(\mathrm{pmol} / \mathrm{l})$ & $122.9 \pm 64.9^{\mathrm{a}}$ & $71.6 \pm 61.2$ & $92.6 \pm 67.5^{\mathrm{a}, \mathrm{b}}$ \\
Total glucose AUC $(\mathrm{mmol} / \mathrm{l} \times \min )$ & $1,290 \pm 386$ & $1,346 \pm 472$ & $1,312 \pm 418$ \\
Total insulin AUC $(\mathrm{pmol} / 1 \times \min )$ & $105,443 \pm 17,031^{\mathrm{a}}$ & $72,653 \pm 15,027$ & $85,736 \pm 18,530^{\mathrm{a}, \mathrm{b}}$ \\
HOMA-IR index & $4.55 \pm 1.78^{\mathrm{c}}$ & $2.45 \pm 1.45$ & $3.29 \pm 1.86^{\mathrm{a}, \mathrm{b}}$ \\
\hline
\end{tabular}

Values are means $\pm \mathrm{SD}$

${ }^{a}$ Significantly different from $7-8$ h sleeping group $(p<0.05)$

${ }^{\mathrm{b}}$ Significantly different from $5-6 \mathrm{~h}$ sleeping group $(p<0.05)$

${ }^{\mathrm{c}}$ Significantly different from $7-8 \mathrm{~h}$ sleeping group $(p<0.01)$

Tables 3 and 4 present the mean results for some glucose homeostasis indicators between the three sleeper groups in men and women. We found that fasting plasma glucose and insulin concentrations, total insulin AUC and the HOMA-IR index were significantly higher in short and long sleepers compared with 'normal' sleepers in both sexes, whereas total glucose AUC was not different between groups. Furthermore, fasting plasma glucose and insulin concentrations, total insulin AUC and the HOMA-IR index were significantly higher in the short sleepers compared with long sleepers in both sexes.

As depicted in Figs. 1 and 2, short sleepers experienced significantly higher insulin levels during the OGTT, as reflected by the higher mean total insulin AUC $(p<0.05)$. In addition, in the latter phase of the OGTT, short sleepers were characterised by a more pronounced decline in blood glucose, resulting in a significantly greater glucose concentration span, measured as the difference between maximal and minimal glucose levels in both sexes $(p<0.05)$. In the same manner, the $G_{\mathrm{ABF}}$ was significantly higher in short $(p<0.01)$ and long sleepers $(p<0.05)$ compared with 'normal' sleepers, and significantly higher in short compared with long sleepers in both sexes $(p<0.05$; Fig. 3$)$.

\section{Discussion}

The present study provides evidence to the effect that short and long sleep times are associated with the presence of type 2 diabetes/IGT in adults, even after adjustment for potential confounders. Moreover, the adjustment for adiposity indices did not attenuate the association of sleep time with type 2 diabetes/IGT, implying that confounding by adiposity is unlikely. The data also suggest that chronic lack of sleep is a stimulus which may destabilise the profile of blood glucose to a greater extent at the end of the oral glucose load. Indeed, short sleepers presented lower glucose concentrations towards the end of the OGTT.

We are only beginning to recognise the hormonal and metabolic implications of sleep curtailment. Physiological data suggest that short-term partial sleep restriction leads to striking alterations in metabolic and endocrine functions, including decreased glucose tolerance, insulin resistance, increased sympathetic tone, elevated cortisol concentrations and decreased leptin and increased ghrelin levels $[9,10,13$, 25]. Thus, one could speculate that chronic lack of sleep represents a stress factor stimulating appetite, promoting weight gain and impairing glycaemic regulation, with a

Table 4 Differences for some glucose homeostasis indicators between short (5-6 h), 'normal' (7-8 h) and long (9-10 h) sleeper groups of women

\begin{tabular}{llll}
\hline & \multicolumn{2}{l}{ Sleeping time $(\mathrm{h})$} & \\
\cline { 2 - 4 } & $5-6(n=42)$ & $7-8(n=292)$ & $9-10(n=83)$ \\
\hline Fasting glucose level $(\mathrm{mmol} / \mathrm{l})$ & $5.71 \pm 0.54^{\mathrm{a}}$ & $5.19 \pm 0.63$ & $5.40 \pm 0.71^{\mathrm{a}, \mathrm{b}}$ \\
Fasting insulin level $(\mathrm{pmol} / \mathrm{l})$ & $118.6 \pm 66.2^{\mathrm{a}}$ & $70.0 \pm 60.4$ & $96.5 \pm 67.9^{\mathrm{a}, \mathrm{b}}$ \\
Total glucose AUC $(\mathrm{mmol} / 1 \times \min )$ & $1,319 \pm 360$ & $1,367 \pm 369$ & $1,348 \pm 385$ \\
Total insulin AUC $(\mathrm{pmol} / 1 \times \min )$ & $107,009 \pm 16,745^{\mathrm{a}}$ & $71,035 \pm 15,140$ & $88,241 \pm 17,447^{\mathrm{a}, \mathrm{b}}$ \\
HOMA-IR index & $4.33 \pm 1.63^{\mathrm{c}}$ & $2.36 \pm 1.42$ & $3.35 \pm 1.81 \mathrm{~b}^{\mathrm{a}, \mathrm{b}}$ \\
\hline
\end{tabular}

Values are means $\pm \mathrm{SD}$

${ }^{a}$ Significantly different from $7-8$ h sleeping group $(p<0.05)$

${ }^{\mathrm{b}}$ Significantly different from $5-6 \mathrm{~h}$ sleeping group $(p<0.05)$

${ }^{\mathrm{c}}$ Significantly different from $7-8 \mathrm{~h}$ sleeping group $(p<0.01)$ 

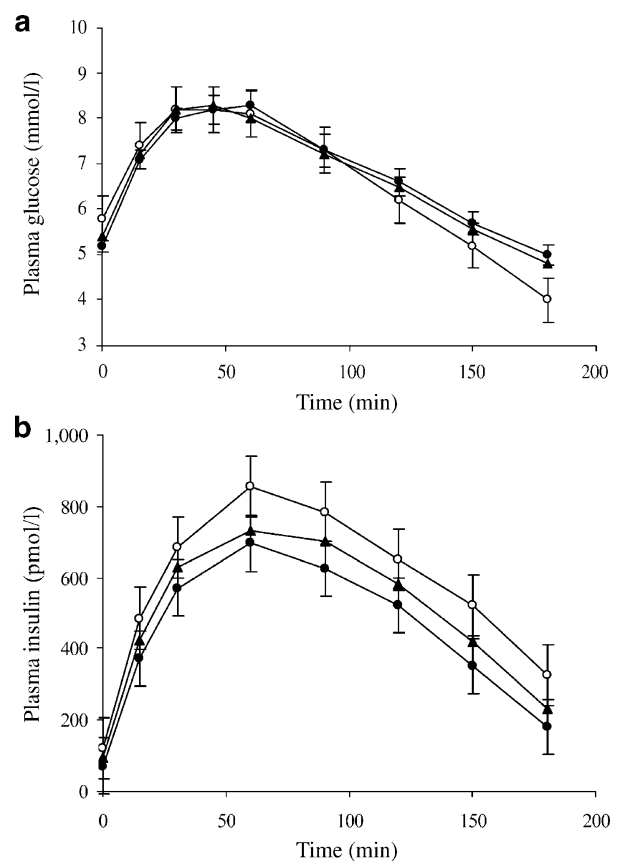

Fig. 1 Mean plasma glucose (a) and insulin concentrations (b) during the OGTT for short (5-6 h, $n=42$; open circles), 'normal' (7-8 h, $n=$ 239; closed circles) and long sleepers (9-10 h, $n=42$; triangles) in men. Means \pm SD

subsequently increased risk of IGT and eventually type 2 diabetes.

Although literature is scarce regarding whether the adverse effects of short sleep duration on glucose metabolism differ between acute and chronic sleep loss, it seems that some degree of adaptation might occur with time. In the short term, two well-controlled laboratory studies of healthy young men submitted to sleep curtailment for 26 days observed that sleep restriction resulted in higher glucose levels and lower insulin levels, leading to decreased glucose tolerance $[9,25]$. On the other hand, preliminary data have shown that young healthy participants of both sexes who voluntarily curtail their sleep on a chronic basis, i.e. $<6.5 \mathrm{~h}$ per night for at least 6 months, have a glucose response to i.v. glucose similar to that of participants with habitual sleep times between 7.5 and $8.5 \mathrm{~h}$, but at the cost of a higher insulin secretion [26]. Thus, the reduction in glucose tolerance to an i.v. glucose load and the decrease in the acute insulin response observed after short-term sleep restriction may in the long run lead to a reduction in insulin sensitivity. Over time, when lack of sleep becomes more chronic, insulin resistance may develop. Results of the present study provide supportive evidence for a role of chronic short sleep duration in the risk of insulin resistance and type 2 diabetes.

The mechanisms mediating the association of long sleep time with type 2 diabetes/IGT are more speculative or unknown. Seven days of extending time in bed to $12 \mathrm{~h}$ per night was not associated with evidence of glucose intolerance [25]. Besides, Nurses' Health Study participants who reported sleeping $9 \mathrm{~h}$ or more per night reported $15 \%$ less physical activity per week than those sleeping $7-8 \mathrm{~h}$ per night [5]. This might lead to impaired glucose regulation through direct or indirect effects of physical inactivity. Nevertheless, we adjusted for physical activity level in the present study. It is not excluded that some unmeasured variables might confound this association. However, the explanation of the increased risk of type 2 diabetes/IGT associated with long sleep time remains speculative at the moment.

Among the theories of appetite control, the glucostatic theory proposed by Mayer [27] suggests that a low absolute glucose concentration and a low arterio-venous glucose difference (an index of the rate of glucose utilisation) are associated with increases in hunger and energy intake. In addition, transient declines in blood glucose of about $10 \%$ have been observed 5-6 min before each meal or foodseeking behaviour in rats [28-30]. Similar results were obtained in humans who were blinded as to the time of day. In the latter case, the initiation of meals and perception of hunger were synchronised with transient and dynamic blood glucose declines [31-33]. In this respect, the influence of chronic short sleep duration on body weight regulation could thus be associated with glycaemic fluctuations. However, future studies should consider combining

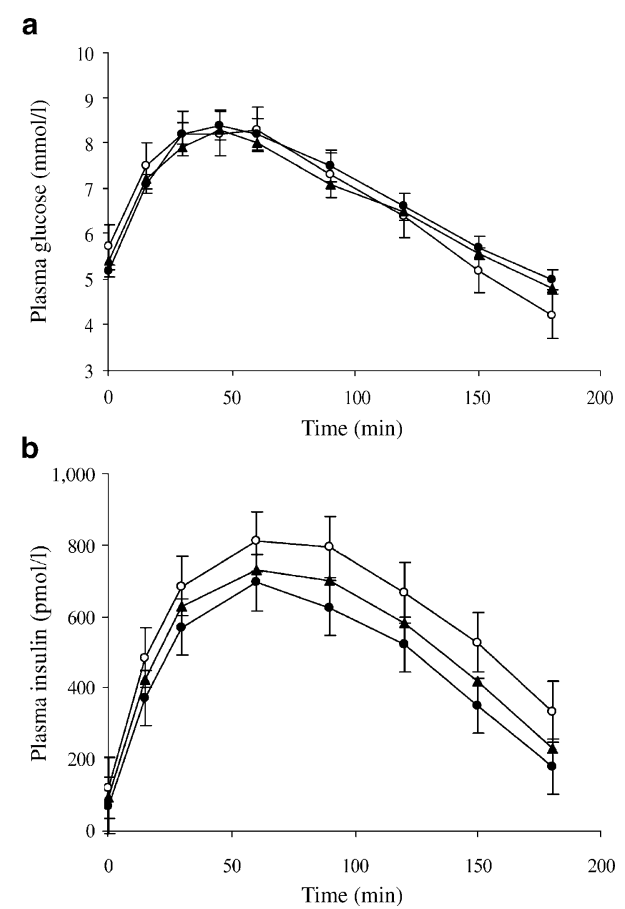

Fig. 2 Mean plasma glucose (a) and insulin concentrations (b) during the OGTT for short (5-6 h, $n=42$; open circles), 'normal' (7-8 h, $n=$ 292; closed circles) and long sleepers (9-10 h, $n=83$; triangles $)$ in women. Means \pm SD 


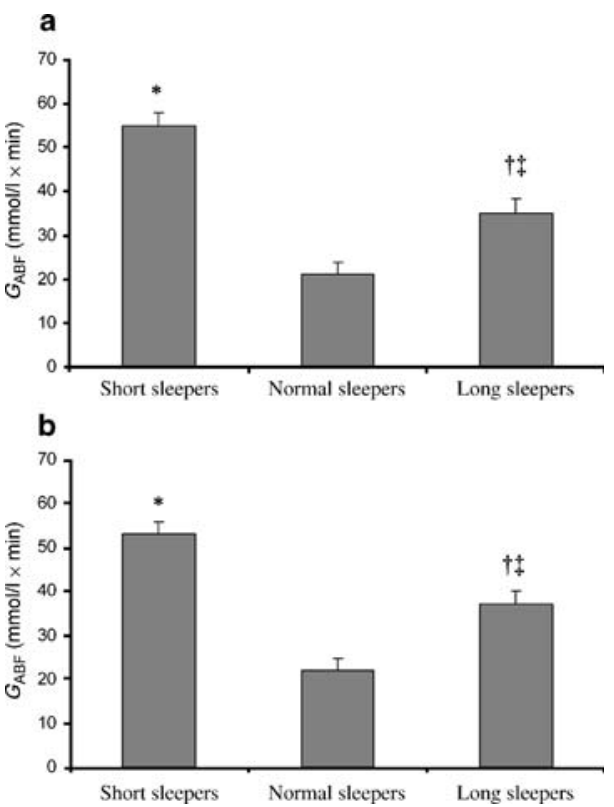

Fig. 3 Mean $G_{\mathrm{ABF}}$ for short (5-6h), 'normal' (7-8 h) and long sleepers $(9-10 \mathrm{~h})$ in men (a; $n=42,239$ and 42, respectively) and women (b; $n=$ 42, 292 and 83, respectively). Means \pm SEM. "Significantly different from 'normal' sleepers $(p<0.01)$. 'Significantly different from 'normal' sleepers $(p<0.05)$. ${ }^{\ddagger}$ Significantly different from short sleepers $(p<0.05)$

validated visual analogue scales for the measurement of hunger and desire to eat with an OGTT in different sleeper groups. Although an OGTT provides standardised conditions to evaluate glucose homeostasis, it is possible that a standardised meal might better represent normal glycaemic responses and could potentially increase the ability to predict which individuals are at greater risk of gaining weight. These studies should be done using a prospective design, including an objective assessment of sleep duration, measuring several appetite-related hormones, and with a focus on adolescents and younger children, who may be more vulnerable to the consequences of sleep loss.

All together, our results corroborate a growing body of evidence suggesting that short sleep duration increases the risk of developing diabetes [5, 34-37]. It is noteworthy that U-shaped associations have been generally observed for the relationships between sleep duration and type 2 diabetes [35], BMI [10], coronary heart disease [4] and all-cause mortality [6]. Thus, it seems that there may be an 'optimal sleeping time' for the prevention of common diseases and premature death. However, randomised controlled studies will be necessary to address whether increasing sleep time could improve glucose homeostasis, help people to lose weight or prevent weight gain, and contribute to one's overall health.

One of the limitations of this study is its sample size, which limits the generalisability of our results to the whole population. In addition, because this was a cross-sectional study, the temporal relationship is unknown. We also have to keep in mind that sleep duration was assessed from a questionnaire and was not measured. However, actigraphic studies have demonstrated the validity of self-reported sleep time [38]. The present study was based on adults, aged 2164 years, and we should be cautious in extrapolating the findings to other age groups. Finally, the possibility of a confounding effect in the relationship of sleep time with type 2 diabetes/IGT by unmeasured variables, such as sleep-disordered breathing, insomnia or depression, cannot be excluded. On the other hand, previous data showed that obstructive sleep apnoea/hypopnoea, insomnia and depressive symptoms had no meaningful effect on the association between sleep time and type 2 diabetes/IGT [36]. Indeed, it seems that much of the reduction in sleep time reflects voluntary sleep restriction, with $43 \%$ of adults reporting that they often stay up later than they should watching television or using the Internet, and $45 \%$ reporting that they sleep less to get more work done [39].

In conclusion, the present study (1) provides evidence to the effect that short and long sleep times are associated with type 2 diabetes/IGT in adults, even after adjustment for confounders; and (2) suggests that chronic lack of sleep can influence blood glucose, as lower plasma glucose concentrations towards the end of the OGTT were observed in short sleepers compared with 'normal' and long sleepers. Hence, the increase in energy intake and weight gain might be an unfortunate solution to restore glucose homeostasis in a context where insufficient sleep time becomes ingrained in the lifestyle of an individual. However, due to the preliminary nature of these findings, they need to be followed up by more careful studies to validate their relevance.

Acknowledgements J.-P. Chaput is supported by a studentship from the Laval Hospital Research Center, J.-P. Després is supported by Pfizer, Provigo, and the Foundation of the Quebec Heart Institute, C. Bouchard is partly supported by the George A. Bray Chair in Nutrition, and A. Tremblay is partly funded by the Canada Research Chair in Physical Activity, Nutrition, and Energy Balance. The authors express their gratitude to the participants for their excellent collaboration and the staff of the Physical Activity Sciences Laboratory for their contribution to this study. We especially thank G. Thériault, G. Fournier, M. Chagnon, L. Allard and C. Leblanc for their help in the collection and analysis of the data.

Duality of interest The authors declare that there is no duality of interest associated with this manuscript.

\section{References}

1. Bonnet MH, Arand DL (1995) We are chronically sleep deprived. Sleep 18:908-911

2. Chokroverty S (1999) Sleep disorders medicine: basic science, technical considerations, and clinical aspects, 2nd edn. Butterworth and Heinemann, Boston, MA, pp 14-16

3. Bliwise DL (1996) Historical change in the report of daytime fatigue. Sleep 19:462-464 
4. Ayas NT, White DP, Manson JE et al (2003) A prospective study of sleep duration and coronary heart disease in women. Arch Intern Med 163:205-209

5. Ayas NT, White DP, Al-Delaimy WK et al (2003) A prospective study of self-reported sleep duration and incident diabetes in women. Diabetes Care 26:380-384

6. Tamakoshi A, Ohno Y; JACC Study Group (2004) Self-reported sleep duration as a predictor of all-cause mortality: results from the JACC study, Japan. Sleep 27:51-54

7. Patel SR, Ayas NT, Malhotra MR et al (2004) A prospective study of sleep duration and mortality risk in women. Sleep 27:440-444

8. Hasler G, Buysse DJ, Klaghofer R (2004) The association between short sleep duration and obesity in young adults: a 13year prospective study. Sleep 27:661-666

9. Spiegel K, Tasali E, Penev P, Van Cauter E (2004) Brief communication: sleep curtailment in healthy young men is associated with decreased leptin levels, elevated ghrelin levels, and increased hunger and appetite. Ann Intern Med 141:846-850

10. Taheri S, Lin L, Austin D, Young T, Mignot E (2004) Short sleep duration is associated with reduced leptin, elevated ghrelin, and increased body mass index. PLoS Med 1:e62

11. Vorona R, Winn M, Babineau T, Eng B, Feldman H, Ware J (2005) Overweight and obese patients in a primary care population report less sleep than patients with a normal body mass index. Arch Intern Med 165:25-30

12. Gangwisch JE, Malaspina D, Boden-Albala B, Heymsfield SB (2005) Inadequate sleep as a risk factor for obesity: analyses of the NHANES I. Sleep 28:1289-1296

13. Chaput JP, Després JP, Bouchard C, Tremblay A (2007) Short sleep duration is associated with reduced leptin levels and increased adiposity: results from the Quebec Family Study. Obesity 15:253-261

14. Bouchard C (1996) Genetic and body fat content. Prog Obes Res 5:33-41

15. The Airlie (VA) Consensus Conference (1988) Standardization of anthropometric measurements. Human Kinetics Publishers, Champaign, IL

16. Behnke AR, Wilmore JH (1974) Evaluation and regulation of body build and composition. In: Behnke AR (eds) Evaluation and regulation of body build and composition. Prentice-Hall, Englewood Cliffs, NJ, pp 20-37

17. Meneely GR, Kaltreider NL (1949) Volume of the lung determined by helium dilution. J Clin Invest 28:129-139

18. Siri WE (1956) The gross composition of the body. Adv Biol Med Phys 4:239-280

19. Richterich R, Dauwwalder H (1971) Zur bestimmung der plasmaglukose-konzentration mit der hexokinase-glucose-6-phosphat-deshydrogenase-methode. Schweiz Med Wochenschr 101:615-618

20. Desbuquois B, Aurbach GD (1971) Use of polyethylene glycol to separate free and antibody-bound peptide hormones in radioimmunoassays. J Clin Endocrinol Metab 37:732-738

21. Matthews DR, Hosker JP, Rudenski AS, Naylor BA, Treacher DF, Turner RC (1985) Homeostasis model assessment: insulin resistance and beta-cell function from fasting plasma glucose and insulin concentrations in man. Diabetologia 28:412-419

22. American Diabetes Association (1997) Report of the expert committee on the diagnosis and classification of diabetes mellitus. Diabetes Care 20:1183-1197

23. Alberti KG, Zimmet PZ (1998) Definition, diagnosis and classification of diabetes mellitus and its complications, part 1 : diagnosis and classification of diabetes mellitus provisional report of a WHO consultation. Diabet Med 15:539-553

24. Hardin JW, Hilbe JM (2003) Generalized estimating equations. Chapman \& Hall/CRC, New York, NY

25. Spiegel K, Leproult R, Van Cauter E (1999) Impact of sleep debt on metabolic and endocrine function. Lancet 354:1435-1439

26. Mander B, Colecchia E, Spiegel K, Kim R, Sannar E, Van Cauter E (2001) Short sleep: a risk factor for insulin resistance and obesity. Diabetes 50(Suppl 2):A45

27. Mayer J (1953) Glucostatic mechanism of regulation of food intake. N Engl J Med 249:13-16

28. Louis-Sylvestre J, Le Magnen J (1980) A fall in blood glucose level precedes meal onset in free-feeding rats. Neurosci Biobehav Rev 4:13-15

29. Campfield LA, Smith FJ (1986) Functional coupling between transient declines in blood glucose and feeding behavior: temporal relationships. Brain Res Bull 17:427-433

30. Campfield LA, Smith FJ (1990) Transient declines in blood glucose signal meal initiation. Int J Obes 14:15-31

31. Campfield LA, Smith FJ, Rosenbaum M, Hirsch J (1996) Human eating: evidence for a physiological basis using a modified paradigm. Neurosci Biobehav Rev 20:133-137

32. Melanson KJ, Westerterp-Plantenga MS, Campfield LA, Saris WH (1999) Blood glucose and meal patterns in time-blinded males, after aspartame, carbohydrate, and fat consumption, in relation to sweetness perception. Br J Nut 82:437-446

33. Melanson KJ, Westerterp-Plantenga MS, Saris WH, Smith FJ, Campfield LA (1999) Blood glucose patterns and appetite in timeblinded humans: carbohydrate versus fat. Am J Physiol 277: R337-R345

34. Knutson KL, Ryden AM, Mander BA, Van Cauter E (2006) Role of sleep duration and quality in the risk and severity of type 2 diabetes mellitus. Arch Intern Med 166:1768-1774

35. Yaggi HK, Araujo AB, McKinlay JB (2006) Sleep duration as a risk factor for the development of type 2 diabetes. Diabetes Care 29:657-661

36. Gottlieb DJ, Punjabi NM, Newman AB et al (2005) Association of sleep time with diabetes mellitus and impaired glucose tolerance. Arch Intern Med 165:863-868

37. Mallon L, Broman JE, Hetta J (2005) High incidence of diabetes in men with sleep complaints or short sleep duration. Diabetes Care 28:2762-2767

38. Lockley SW, Skene DJ, Arendt J (1999) Comparison between subjective and actigraphic measurement of sleep and sleep rhythms. J Sleep Res 8:175-183

39. National Sleep Foundation (2006) 'Sleep in America' poll. National Sleep Foundation, Washington, DC 